\title{
Narrative experiences and effects of media stories: An introduction to the special issue
}

\author{
HELENA BILANDZIC and SUSANNE KINNEBROCK \\ E-mails: helena.bilandzic@uni-erfurt.de; s.kinnebrock@isk.rwth-aachen.de
}

One of the most important functions of media is to inform and connect citizens, enabling them to participate in democratic processes and providing the grounds for integration and social cohesion. While media stories support and uphold these functions, they can also hinder these functions when stories present distorted views on social reality or promote anti-social behavior. At the heart of these processes, however, is the issue of how media stories contribute to shaping their audience's knowledge, worldviews, and norms. In recent years, more attention has been paid to fictional and factual media stories and their real-life consequences (for an overview, see Green, Strange, and Brock, 2002). A vast number of studies demonstrates that stories are powerful in altering the audience's knowledge about the real world and facilitate changes in attitudes (Appel, 2008; Green and Brock, 2000; Strange and Leung, 1999). While the distinction of fact and fiction is clear on the production side, it seems next to irrelevant for story experience and effects on the audience side people learn just as much about their actual world from fictional stories as from factual stories (Green, Garst, Brock, and Chung, 2006). More surprisingly, audiences acquire beliefs from stories that contradict common knowledge (Prentice, Gerrig, and Bailis, 1997) or that are even false (Green, 2008; Maleckar and Appel, 2008). Stories have the power to create strong and enduring beliefs that grow increasingly stronger over time (Appel and Richter, 2007) and produce cumulative cultivation effects when audiences repeatedly consume similar content patterns present in specific genres (Bilandzic and Busselle, 2008).

An explanation of these results requires exploring the mechanisms through which people understand and appropriate story content. The dominant view on mechanisms presently builds on the phenomenological experience that viewers and readers have with narratives: When immersed in a story, audience members experience story events in an immediate and intensive manner and are able to understand emotions presented through fictional characters in a way similar to direct non-medi- 
ated experience (Green and Brock, 2002). Terms such as being "transported" (e.g., Gerrig, 1993; Green and Brock, 2002) or "lost" (Nell, 1988 ) in the narrative world capture the sense of full absorption of audience members who are capable of remaining in a state of oblivious alertness for hours. Narrative effects are often seen to emerge from a reduction in counterarguing and an increase in elaboration, which both result from intense narrative engagement (Green and Brock, 2000; Slater and Rouner, 2002), or from the simulation of mediated social situations, which enhances empathic abilities in the audience (Mar and Oatley, 2008).

The goal of this special issue on narrative experiences and effects of media stories is to further the discussion about how media stories impact knowledge and attitudes, or, more broadly, norms, values, and morals of audiences. While our knowledge about story effects is constantly growing, many pressing questions remain unanswered.

One of these questions regards the nature of narrative experience. The focus of research in narrative persuasion has been on immersive experiences such as transportation; however, other types of experience are certainly conceivable and will mediate effects in their own ways. The contribution by Monika Suckfüll and Michael Scharkow addresses this issue. Involvement in narratives is recognized as a multidimensional, dynamic mode. Viewers are regarded as competent and creative users of narrative content who adapt the mode of reception to both content and their own needs. Suckfüll and Scharkow offer an integrative approach to narrative involvement that encompasses usually distinct notions and helps to create an overall, holistic view of how viewers perceive films. The measurement they present, the Modes of Reception Inventory, comprises four dimensions of involved viewing: Identity work (which happens when viewers use films to form and stabilize their own identities), In-Emotion (acting out emotions in a secure fictional context), Imagination (imaging alternative plot lines), and Production (reflection of the film as artifact with particular aesthetic qualities and contexts, such as directors, actors, locations). As narrative persuasion has so far focused on immersive experiences, this inventory will be helpful to future effects research by providing a tested instrument encompassing the notions of being in a narrative, criticizing, and connecting with narratives.

The second contribution by Anneke de Graaf, Hans Hoeken, José Sanders, and Hans Beentjes also considers narrative engagement as a multifaceted construct, but focuses on immersive experiences rather than capturing the full range of experiential phenomena as Suckfüll and Scharkow do. For the most part, immersive experiences are - even if composed of different aspects like cognition, emotion, and imagery in transportation theory - treated as holistic judgments of narrative ex- 
perience; only recently have concepts and instruments been developed that systematically capture dimensions of narrative engagement (Busselle and Bilandzic, in print). De Graaf and colleagues investigate the role of such dimensions of narrative engagement for persuasive effects. In the past, it proved to be difficult to manipulate transportation, which is necessary for creating a causal logic for effects. This contribution however successfully manages to manipulate engagement and its different facets. Instructing the audience to single out specific types of sentences lessened the feeling of being present in the narrative world, while grammar and spelling errors in the text lowered attention paid to the story. However, emotional engagement could not be manipulated, but instead was revealed to be the only narrative experience to mediate attitudinal effects. Therefore, not all dimensions of narrative engagement may be considered as mechanisms through which narrative effects emerge emotions seem to play the most important role. This study stresses the need to explore narrative engagement more thoroughly and separate the processes that actually mediate effects from those that merely accompany the processing of stories.

The theoretical contribution by Manuela Glaser, Bärbel Garsoffky, and Stefan Schwan addresses another open question that increases in relevance as we learn more about audience experience: How do characteristics of story content contribute to narrative effects? Little is known about which elements of stories are effective. Frequently, the experiential magic of a good story is reflected in commercial successes of stories (Green, 2004) and described by narratologists (e. g., Prince, 1999); however, a systematic empirical investigation of how audiences actually perceive story characteristics continues to elude us. Therefore, the approach used by Glaser, Garsoffky, and Schwan is a step toward systematically describing which story elements lead to which experiences and effects. They choose a specific case of narratives - shows on science education - and elaborate how stories may facilitate knowledge acquisition. Four distinct features of science stories are outlined: dramatization, emotionalization, personalization, and fictionalization. Furthermore, they also outline possible consequences for interest, attention, elaboration, and representation of scientific facts that may define future research programs.

While the contributions by de Graaf et al. and Glaser et al. deal with rather traditional notions of media effects on attitudes and learning, the final two articles of this special issue are concerned with narratives as options for moral reflection and acquiring social skills through mediated social situations. Raymond A. Mar, Keith Oatley, and Jordan B. Peterson start from the observation that readers of fiction display better abilities to empathize with others and understand social situations. This 
relationship may be interpreted as a cumulative effect of many instances of simulating social situations and opportunities for empathic emotions. Equally plausible however is the notion that personality traits increase both empathy and exposure to fiction; this possibility is however ruled out by this study. The authors find that even after controlling for openness, gender, and the tendency to perceive narrative engagement, reading fiction is correlated with empathy. The finding that the relationship between social ability and reading fiction is not a spurious one is indeed an encouraging starting point from which to explore the causal direction and possible mediators (such as narrative engagement, involvement, etc.) of this relationship.

The final contribution turns to a narrative content type that goes back to one of the traditional functions of stories, that is, to teach appropriate conduct in society and provide criteria for moral judgment. Tonny Krijnen and Ed Tan select a popular television format to explore moral functions of stories: As a hybrid genre, reality game shows are characterized by blurring boundaries between fact and fiction. They combine documentary elements focusing on the assumed authenticity of the participants' conduct or emotions with a narrative dramaturgy that provides the participants with imposed roles and an artificial setting. Krijnen and Tan analyze the Dutch reality game show "The Golden Cage" as a laboratory in which moral conflicts are simulated. Immoral conduct and even malevolent pleasure of immorally acting participants initially seem to dominate in this show. However, as soon as narrative realism is taken into account (including a dramatic structure and archetypical characters), the participants' conduct can be analyzed in terms of successful performances in line with the created characters. Taking this perspective, Krijnen and Tan provide additional explanations as to the entertainment and education value of watching reality game shows. The impeccability of performance can be appreciated and the hope that the authentic person shines through the performance may motivate viewers to continue watching. Ultimately, reflections on differences in natural and scripted acting may occur. As a result, reality game shows may not only be regarded as a platform for the presentation of primarily socially problematic conduct, but also as an emotional laboratory for the playful exploration of identity politics.

This special issue provides new insights into research on narrative experience and effects. This new and dynamic field is well reflected in the contributions that encompass very different narrative effects such as learning facts, complex moral reflection, different narrative experiences, immersive and analytic modes of reception, as well as relations to stable personality traits. Specifically, many new research questions emerge from these articles: What is the relationship between story characteristics, au- 
dience experiences, and effects? How can insights from research on fictional stories be used for constructing educational and news stories? What theories and methods are required in order to investigate effects of narratives on social skills and moral reflection as opposed to "traditional" effects on knowledge and attitudes? This research agenda calls for a creative scholarly effort that pays specific attention to open-minded collaboration across interdisciplinary borders between communication research, psychology, film studies, literature, linguistics, philosophy, and education.

\section{Bionotes}

Helena Bilandzic is Assistant Professor at the Department of Media and Communication, University of Erfurt, Nordhäuser Str. 63, 99089 Erfurt, Germany.

Susanne Kinnebrock is Professor at the Institute for Language and Communication Studies, RWTH Aachen University, Theaterplatz 14, 52062 Aachen, Germany.

\section{References}

Appel, M. (2008). Fictional narratives cultivate just world beliefs. Journal of Communication, $58,62-83$.

Appel, M. \& Richter, T. (2007). Persuasive effects of fictional narratives increase over time. Media Psychology, 10, 113-134.

Bilandzic, H. \& Busselle, R. W. (2008). Transportation and transportability in the cultivation of genre-consistent attitudes and estimates. Journal of Communication, $58,508-529$.

Busselle, R. W. \& Bilandzic, H. (in print). Measuring narrative engagement. Media Psychology.

Gerrig, R. J. (1993). Experiencing narrative worlds. New Haven, CT: Yale University Press.

Green, M. C. (2004). Transportation into narrative worlds: The role of prior knowledge and perceived realism. Discourse Processes, 38, 247-266.

Green, M. C. (2008). Narrative impact: Effects of fiction and falsehood. Paper presented at the International Congress of Psychology, Berlin.

Green, M. C. \& Brock, T. C. (2000). The role of transportation in the persuasiveness of public narratives. Journal of Personality and Social Psychology, 79, 701-721.

Green, M. C. \& Brock, T. C. (2002). In the mind's eye. Transportation-imagery model of narrative persuasion. In M. C. Green, J. J. Strange, \& T. C. Brock (Eds.), Narrative impact: Social and cognitive foundations (pp. 315-341). Mahwah, NJ: Lawrence Erlbaum.

Green, M. C., Garst, J., Brock, T. C., \& Chung, S. (2006). Fact versus fiction labeling: Persuasion parity despite heightened scrutiny of fact. Media Psychology, 8(3), $267-285$.

Green, M. C., Strange, J., \& Brock, T. C. (Eds.). (2002). Narrative impact: Social and cognitive foundations. Mahwah, NJ: Lawrence Erlbaum. 
Maleckar, B. \& Appel, M. (2008). The impact of information validity and need for affect on the persuasion through fiction. Paper presented at the International Congress of Psychology, Berlin.

Mar, R. A. \& Oatley, K. (2008). The function of fiction is the abstraction and simulation of social experience. Perspectives on Psychological Science, 3, 173-192.

Nell, V. (1988). Lost in a book. The psychology of reading for pleasure. New Haven, CT: Yale University Press.

Prentice, D. A., Gerrig, R. J., \& Bailis, D. S. (1997). What readers bring to the processing of fictional texts. Psychonomic Bulletin and Review, 4(3), 416-420.

Prince, G. (1999). Revisiting narrativity. In W. Grünzweig \& A. Solbach (Eds.), Grenzüberschreitungen. Narratologie im Kontext [Transcending boundaries. Narratology in context] (pp. 43-51). Tübingen: Gunter Narr.

Slater, M. D. \& Rouner, D. (2002). Entertainment-education and elaboration likelihood: Understanding the processing of narrative persuasion. Communication Theory, 12(2), 173-191.

Strange, J. J. \& Leung, C. C. (1999). How anecdotal accounts in news and in fiction can influence judgments of a social problem's urgency, causes, and cures. Personality and Social Psychology Bulletin, 25, 436-449. 